\author{
А.К. Байсеитова \\ Алматинская академия МВД Республики Казахстан \\ имени Макана Есбулатова, Казахстан, г. Алматы, \\ e-mail: baliya76@mail.ru

\section{ТАКТИЧЕСКИЕ ОСОБЕННОСТИ ПРОВЕАЕНИЯ ОПОЗНАНИЯ}

В статье рассматриваются тактические особенности проведения опознания в уголовном судопроизводстве. Проведен анализ мнений различных ученых относительно классификации Аанного слеАственного Аействия в уголовном процессе. Как и ^юбое Аругое слеАственное Аействие, предусмотренное уголовно-процессуальным законом, предъявление кица Аля опознания по уголовному делу имеет немаловажное значение. Каждое проводимое следственное Аействие характеризуется своей спецификой, и определяется, в частности, такими факторами, как задачи, которые возможно решить посреАством проведения Аанного слеАственного Аействия, его правовой регламентацией, своеобразием круга участников, местом проведения и иными обособленными характеристиками. Так, результаты этого следственного действия могут быть использованы А^я установления некоторых обстоятельств правонарушения, Аействия кажАого из преступников на месте преступления. Информация, полученная при опознании, может способствовать изобличению мица, совершившего преступление. Само преАъявление Аля опознания как следственное действие является среАством собирания доказательств. Следовательно, протокол, в котором зафиксированы сведения, полученные в результате проведения опознания, имеет доказательственное значение, т.е. может использоваться в качестве доказательства. Рассмотрен порядок предъявления Аля опознания живых миц, трупа, предметов и животных.

Кроме того, от специфики проводимого слеАственного Аействия зависит и тактика, избираемая следователем Аля его проведения. Успешно избранная тактика позволяет в итоге Аостичь ту цель, которую ставил следователь при принятии решения о провеАении того или иного слеАственного Аействия.

Кмючевые слова: порядок предъявления для опознания, вещественные доказательства, уголовно-процессуальное законодательство, следственные Аействия, участники уголовного процесса, орган, веАущий уголовный процесс, живые лица, допрос, труп, предметы осмотра.

\author{
A.K. Baiseitova \\ Almaty Academy of the Ministry of internal Affairs \\ of the Republic of Kazakhstan named after Makan Esbulatov, Kazakhstan, Almaty, \\ e-mail: baliya76@mail.ru
}

\title{
The tactical features of the identification
}

The article discusses the tactical and procedural features of identification. The author analyzes the opinions of various scientists regarding the classification of this investigative action in criminal proceedings. Each investigative action carried out is characterized by its own specifics, and, in particular, is determined by such factors as the tasks that can be solved by conducting this investigative action, its legal regulation, the uniqueness of the circle of participants, the venue and other separate characteristics. Like any other investigative action provided for by the criminal procedure law, the presentation of a person for identification in a criminal case is not unimportant. So the results of this investigative action can be used to establish certain circumstances of the offense, the actions of each of the criminals at the scene of the crime. Information obtained during identification may help to expose the person who committed the crime. The very presentation for identification as an investigative action is a means of collecting evidence. Therefore, the Protocol, which records the information obtained as a result of identification, has an evidentiary value, i.e. it can be used as evidence. The order of presentation for identification of living persons, corpses, objects and animals is considered.

In addition, the tactics chosen by the investigator for its conduct depend on the specifics of the investigative action. As a result of a well-chosen tactic, it is possible to achieve the goal set by the investigator when making a decision to conduct a certain investigative action. 
Key word: order of presentation for identification, material evidence, criminal procedure legislation, investigative actions, participants in criminal proceedings, body conducting criminal proceedings, living persons, interrogation, corpse, inspection items.

\author{
А.К. Байсеитов \\ Қазақстан Республикасы IIM Мақан Есболатов атындағы \\ Алматы академиясы, Қазақстан, Алматы қ. \\ *e-mail: baliya76@mail.ru
}

Танудың тактикалық ерекшеліктері

\begin{abstract}
Мақалада танудың тактикалық және процессуалдық ерекшеліктері қарастырылады. Қылмыстық процестегі осы тергеу әрекетін жіктеуге қатысты әртүрлі ғалымдардың пікіріне талдау жасалды. Қылмыстық процестік заңында көзделген кез келген басқа тергеу әрекеті сияқты, адамды қылмыстық іс бойынша тану үшін ұсыну тәртібі де маңызды. Жүргізілген әрбір тергеу әрекеті өзінің ерекшелігімен сипатта^ады және, атап айтқанда, осы тергеу әрекетін жүргізу арқылы шешуге болатын міндеттер, оның құқықтық реттелуі, қатысушылар тобының ерекшелігі, өткізілетін орны және басқа да оқшауланған сипаттамалары сияқты факторлармен анықталады. Осылайша, тану үшін ұсыну тергеу әрекетінің нәтижелері құқық бұзушылықтың кейбір жағдайларын анықтау үшін пайдаланылуы мүмкін, қылмыс орнындағы әр қылмыскердің әрекеті. Тану кезінде алынған ақпарат қылмыс жасаған адамды әшкерелеуге ықпал етуі мүмкін. Тергеу әрекеті ретінде тану үшін ұсынудың өзі дәлелдемелер жинау құралы болып табылады. Аемек, тану нәтижесінде алынған мәліметтер жазылған хаттама дәлелдемелік мәнге ие, яғни дәлелдеме ретінде пайдаланылуы мүмкін. Тірі адамдарды, мәйіттерді, заттар мен жануарларды тану үшін ұсыну тәртібі қарастырылды.

Сонымен қатар, тергеуші оны жүргізу үшін таңдаған тактика тергеу әрекетінің ерекшелігіне байланысты. Сәтті таңдалған тактика нәтижесінде тергеуші белгілі бір тергеу әрекетін жүргізу туралы шешім қабылдаған кезде қойған мақсатқа жетуге мүмкіндік береді.

Түйін сөздер: тану үшін ұсыну тәртібі, заттай дәлелдемелер, қылмыстық процестік заңнамасы, тергеу әрекеттері, қылмыстық процеске қатысушылар, қылмыстық процесті жүргізетін орган, тірі аАамдар, жауап алу, мәйіт, заттарды қарап-тексеру.
\end{abstract}

\section{Введение}

Уголовно-процессуальное законодательство Республики Казахстан с целью эффективного, законного и справедливого проведения досудебного расследования по уголовному делу предусматривает проведения ряда самостоятельных следственных действий. Выбор в пользу проведения того или иного следственного действия принадлежит следователю и зависит от конкретной ситуации и стоящих перед следствием задач.

Каждое проводимое следственное действие характеризуется такими факторами, как задачи, которые необходимо решить посредством проведения данного следственного действия, его правовой регламентацией, своеобразием круга участников, местом проведения и иными обособленными характеристиками.

Правовое регулирование проведения каждого следственного действия осуществляет уголовно-процессуальное законодательство, в частности глава 29 уголовно-процессуальный кодекс Республики Казахстан (https://online.zakon.kz/ document/?doc_id=31575252).
Со временем криминалистическая техника стала складываться в виде раздела науки криминалистики, в систему которой, помимо общей теории криминалистики и техники, входят криминалистическая тактика и криминалистическая методика. Однако это понятие продолжало длительное время обозначать часть криминалистики, включающую в себя способы применения для расследования преступлений данных естественных наук медицины, химии, токсикологии, биологии, физики. В первом советском учебнике криминалистики для слушателей правовых вузов по этому поводу говорилось следующее: «Уголовная техника изучает способы применения естественных наук (физики, химии, биологии и т. д.) к расследованию преступлений» (Вышинский 1935, Т.1: 67). Затем под криминалистической техникой стали понимать систему приемов исследования вещественных доказательств в целях розыска, опознания и идентификации лиц и предметов по следственным делам. Как сообщает Р.С. Белкин в первом томе своего фундаментального трехтомного курса криминалистики (Белкин 1993: 272-273), в 1938 г. по ряду про- 
анализированных им причин понятие криминалистической техники исчезло из отечественной научной и учебной криминалистической литературы. Это, разумеется, не означало, что ее проблемы не продолжали изучаться в рамках других разделов криминалистики. Вновь это понятие введено в научный оборот С. П. Митричевым в 1958 г. В настоящее время правомерность этого никем под сомнение не ставится, обозначая один из разделов криминалистики. В конце 80-х и начале 90-х гг. отдельные ученые стали говорить (в учебной и методической литературе) о криминалистической технике как о технико-криминалистическом обеспечении раскрытия и расследования преступлений, сокращенно ТКС (А. Ф. Волынский, А. С. Шаталов и др.). Под ТКО ими понимается вид деятельности, «направленный, с одной стороны, на создание условий постоянной готовности ее субъектов к применению средств и методов криминалистической техники, а с другой - на реализацию таких условий в каждом конкретном случае раскрытия и расследования преступлений» (Волынский 1999: 23). Совершенно очевидно, что в таком контексте ТКО не раздел науки криминалистики, а лишь один из объектов, изучаемых таким ее разделом, как криминалистическая техника.

В зарубежной специальной литературе чаще всего вместо понятия «криминалистическая техника» используется или выступает его синонимом категория «естественнонаучная криминалистика». Под ней понимается «система знаний и методов всех естественных и технических наук в той части и объеме, в которых они могут быть использованы в целях раскрытия, расследования и предупреждения преступлений». Немецкий ученый-криминалист и судебный эксперт Клаус Дитер Поль так пишет о предметной области этого раздела криминалистики: «Естественнонаучная криминалистика (в англосаксонской терминологии «судебная наука») занимается реконструкцией преступного деяния на основе исследования вещественных доказательств» (Поль 1985: 15).

Р.С. Белкин считает, что криминалистическая технология - это система научных положений и основанных на них технических (в широком смысле слова) средств и приемов, а также приемов, предназначенных для сбора, использования и изучения доказательств в целях раскрытия и предупреждения преступлений. Это определение фокусируется на прикладном характере данного раздела криминологии и на более широком понимании самих технических средств как таковых. Определение Р. С. Белкина более точ- но и полно отражает современное содержание криминалистической техники как отрасли науки криминалистики, но с единственным уточнением, вытекающим из ранее сформулированного определения предмета криминалистики в целом. Предметной областью криминалистики в настоящее время является не только раскрытие и расследование преступлений, но и более широкое изучение преступлений субъектами этой деятельности с использованием криминалистических средств. Именно поэтому криминалистическая технология «принадлежит» всем субъектам такой деятельности: следователю, дознавателю, специалисту и эксперту, государственному обвинителю и защитнику обвиняемого по уголовному делу. С целью оптимизации соответствующей деятельности этих лиц она изучается и разрабатывается. Конечно, у каждого из этих предметов должна быть своя «техника».

Для каждого из них криминалистическая технология имеет свое значение и свои особенности, обусловленные их функциональными и уголовно-процессуальными обязанностями и возможностями использования достижений данного раздела науки криминалистики в той или иной мере. Прежде чем рассматривать специфику криминалистической технологии отдельных ее субъектов, необходимо очертить систему данного раздела криминалистики. Данный раздел науки криминалистики состоит из приведенного выше определения ее предмета, научных положений и соответствующих технических средств, основанных на них, приемов и приемов сбора, исследования и использования доказательств. Методологической и общетеоретической основой, ядром ее научных положений являются рассмотренная выше трасология, криминалистическая доктрина следов и доктрина криминалистического распознавания. Именно с этих позиций данный раздел науки криминалистики творчески осмысливает возможности использования научных положений и практических достижений систем естественно-технических знаний для изучения преступлений в уголовном судопроизводстве, адаптирует их для этих целей, создает технико-криминалистические средства и методы. Все средства криминалистической технологии, составляющие разработанную, прикладную часть рассматриваемого раздела криминалистики, направлены на их использование в судебных доказательствах, т. е. либо для сбора доказательств (их идентификации, запечатления, фиксации, изъятия), либо для предварительного и экспертного исследования. При этом одни и те 
же средства в широком смысле слова могут быть использованы для достижения всех этих целей (сбор, исследование, использование доказательств). Поэтому система криминалистической техники традиционно строится не на основе целей использования ее средств (хотя такой подход правомерен и встречается в литературе), а на тех отраслях технических и естественных наук и знаний, которые используются для достижения этих целей. По этим основаниям в систему криминалистической техники большинство ученых, помимо трасологии, включают: судебную фотографию, киносъемку и видеозапись, судебную баллистику, криминалистическое исследование письма и документов, судебную гибитологию (отождествление личности по внешним признакам); криминалистическую (уголовную) регистрацию, криминалистическое исследование материалов и веществ. Как и любая иная научнопрактическая система, система криминалистической техники находится в постоянном развитии. Появляются вызванные потребностями практики новые ее элементы (Баев 2001).

\section{Основная часть}

Одним из наиболее действенных инструментов установления обстоятельств по уголовному делу является такое следственное действие, как предъявление для опознания.

Предъявление для опознания - это следственное действие, заключающееся в отождествлении опознающим лицом (свидетелем, потерпевшим, подозреваемым или обвиняемым) ранее воспринимавшегося объекта (человека, трупа человека, каких-либо вещей) по мысленному образу, запечатленному в памяти опознающего. Как правило, опознание человека производится визуальным способом по внешним признакам. Однако, в некоторых следственных ситуациях, оно может быть произведено и по функциональным признакам, например по походке, голосу, речи, их особенностям и дефектам (Нубаева 2009: 138).

Опознание (узнавание по приметам или особенностям) по его месту в системе следственных действий занимает далеко не последнее место и может быть правомерно отнесено к числу неотложных следственных действий по ряду причин (Когамов 2018: 167).

Успех проведения рассматриваемого следственного действия во многом зависит от качества подготовки к нему.

Профессор А.Я. Гинзбург выделяет следующие подготовительные действия:
- выбор момента предъявления для опознания;

- создание обстановки, благоприятной для опознания;

- подбор объектов, подлежащих опознанию;

- проверка научно-технических средств (Гинзбург 1977: 4).

Решение о предъявлении лица для опознания обычно возникает после допроса лица, показания которого показывают, что это лицо при определенных обстоятельствах наблюдало определенный предмет, запомнило некоторые его признаки и приметы и сможет его опознать.

На основе практики можно выделить следующие основные случаи опознания людей:

- лицо, представляемое для опознания, ранее не было известно опознающему лицу, но при определенных обстоятельствах последнему удавалось запомнить какие-либо признаки внешности первого;

- лицо, удостоверяющее личность, знакомо с лицом, представляемым для опознания, но не может назвать свою фамилию, имя и отчество или неправильно называет их;

- идентифицирующее лицо знает представляемого, правильно называет его, но последний отрицает факт знакомства.

Этап подготовки презентации к идентификации имеет большое значение. Проведение данного следственного действия требует особой точности в исполнении процессуальных правил и соблюдения криминалистической техники. Это связано с его уникальностью, которая заключается в том, что при выявлении допущенных процессуальных нарушений и иных отказов повторное предъявление одного и того же лица для установления личности одного и того же лица на основании не имеет смысла (в отличии, например, от осмотра, обыска, допроса, очной ставки, следственного эксперимента, экспертизы и т. д.). Если следственное действие проводится с нарушением, следственная практика и закон не только исключают опознание из состава доказательств, но и категорически отвергают новое, повторное опознание того же лица (ч. 12 ст. 230 УПК РФ).

При подготовке к предъявлению лица для опознания следователь должен определить время и место встречи. При этом желательно создать максимально благоприятные условия для проведения следственного действия. Выберите достаточно большой кабинет, чтобы вместить всех участников расследования.

Очень важной задачей является выбор лиц, 
среди которых будет представлен идентифицируемый объект. Если лицо должно быть предъявлено для опознания, то необходимо найти еще двух лиц, имеющих максимально возможное сходство с опознанным лицом. В Уголовно-процессуальном кодексе нет указания на то, что количество предъявляемых для опознания объектов должно быть ровно три, но на практике чаще всего предъявляется столько объектов из-за того, что очень трудно найти большее количество подобных опознаваемых. Однако всегда следует иметь в виду, что чем больше объектов (в данном случае лиц) представлено для идентификации и чем меньше разница между ними, тем более достоверными можно считать результаты идентификации. Конечно, трудно определить максимальное количество лиц для представления, однако не рекомендуется представлять неоправданно большое их количество, даже если это возможно. В любом случае решение по данному вопросу принимается следователем в зависимости от конкретной ситуации.

При подготовке к предъявлению лиц для опознания следователь должен пригласить в назначенный час двух свидетелей. Если кто-либо из участников данного следственного действия не владеет языком, на котором ведется производство, то приглашается переводчик. Следователь готовит фотооборудование или приглашает специалиста для фотографирования или видеосьемки хода следственного действия. Кроме того, если лицо, удостоверяющее личность, не достигло 14-летнего возраста, для проведения этого следственного действия должен быть приглашен учитель. При допросе таких лиц перед предъявлением их для опознания, а также предъявлении им предметов для опознания следует учитывать их возрастные и индивидуальные особенности, а также степень их развития.

Также необходимо рассмотреть вопрос о месте нахождения опознающего лица, чтобы в ходе подготовки не произошло случайной встречи с другими участниками следственного действия.

Следователь не должен быть чрезмерно осторожным. Бывают случаи, когда человека, явившегося для опознания, выставляют в коридор. Мимо него в кабинет, где будет проходить опознание, опознанного ведут в наручниках в сопровождении охранника или сотрудника милиции (это особенно часто допускается в отделе полиции). Если это происходит случайно, следователь, владея техникой допроса, может исправить ошибку. Но иногда «встреча» организуется намеренно, чтобы опознающий не ошибся и не указал при опознании не на того человека. Если факт такой подготовки выясняется в судебном заседании, суд не признает доказательственной ценности протокола опознания.

Далее важно психологически подготовить опознающее лицо к предстоящей процедуре опознания подозреваемого или обвиняемого. Не будучи психологически заранее подготовленным к признанию, при виде лица, совершившего преступление, опознавательный знак может быть утрачен в результате сильного волнения или под влиянием страха скажут, что среди требований никто не узнает. Перед проведением идентификации необходимо поговорить с идентифицирующим лицом, успокоить его, иначе идентификация может не состояться. Особенно боятся активно показываться на опознании пожилые женщины и молодые девушки. Иногда на практике начинающие следователи совершают ошибку, отводя опознавателя в другую комнату, и упрекают его в трусости. Этого делать ни в коем случае не следует.

В практике известны случаи, когда опознанные в ходе предварительного допроса подробно излагали приметы преступника и выражали уверенность в своей способности знать прошлое; будучи впоследствии приглашенными в кабинет следователя и видя требования к установлению личности лиц, внезапно покидали кабинет, заявив впоследствии, что опасались возможного возмездия со стороны задержанного.

Уголовно-процессуальным кодексом Республики Казахстан в части 11 статьи 230 предусмотрено, что обеспечение признания опознания может осуществляться без визуального наблюдения за опознаваемым лицом. Это своего рода гарантия обеспечения безопасности распознавателя.

Следует иметь в виду, что при производстве каждого следственного действия решаются конкретные задачи, присущие только ему. Поэтому недопустимо решать задачи одного следственного действия при производстве другого. Следственное действие должно быть исследованием, направленным на получение оптимального результата. При выборе из системы предъявления следственных действий для опознания необходимо ориентироваться на:

1) текущую ситуацию;

2) задачи, подлежащие решению;

3) способы выполнения этих задач.

В качестве опознающего лица могут выступать потерпевший, свидетель, подозреваемый (обвиняемый, подсудимый). Субъект, выступающий в роли агента идентификации, должен быть 
предварительно опрошен об обстоятельствах, при которых он ранее наблюдал опознаваемый объект, и о том, какими особыми признаками он может отличить его от аналогичных.

Весь процесс наблюдения и узнавания (неузнавания) опознающим лицом опознаваемого объекта, а также его результаты находятся под непосредственным наблюдением следователя. Он лично воспринимает факт опознания (неопознания) и связанные с этим обстоятельства: условия проведения опознания, внешний вид и иные признаки опознаваемых объектов, степень индивидуальности опознаваемого объекта, т. е. его выделяемость из числа других предъявляемых вместе с ним однородных объектов, и т. д. Это могут быть элементы поведения опознающего лица - так называемые улики поведения, которые во многих случаях имеют существенное доказательственное значение для уголовного дела. Это могут быть и особенности поведения опознающего субъекта, например, как именно он узнал предъявленный ему объект: сразу без колебаний или после долгих раздумий и сомнений (Россинский 2018: 234).

В специальной литературе можно встретить ряд классификаций, касающихся рассматриваемого следственного действия. Наиболее распространенной является классификация, проводимая по объекту опознания. При этом различают опознание живых лиц, опознание трупов, опознание предметов, документов, животных, опознание местности, помещения.

Опознающие предварительно допрашиваются об обстоятельствах, при которых они наблюдали соответствующее лицо или предмет, приметах и особенностях, по которым они могут произвести опознание (Аубакирова 2000).

Если человек во время допроса указывает, что не уверен, может ли он опознать опознанное лицо (объект), то проводить опознание нецелесообразно.

Предварительный допрос опознающего лица является важным этапом подготовки к опознанию. При допросе лицом, ведущим уголовный процесс, должны быть выяснены следующие обстоятельства: насколько знаком допрашиваемому опознаваемый предмет? При каких обстоятельствах и условиях он воспринимал этот предмет раньше? Какие особенности и индивидуальные признаки объекта запечатлеваются в памяти распознавателя? Сможет ли он опознать предмет, предъявленный для опознания? Есть ли у допрашиваемого какие-либо нарушения вос- приятия, которые могут повлиять на идентификацию объекта?

Если опознающее лицо является свидетелем или потерпевшим, то они предупреждаются до установления уголовной ответственности за отказ от дачи показаний и за дачу заведомо ложных показаний. При этом применяется так называемый свидетельский иммунитет, заключающийся в праве не свидетельствовать против себя, своего супруга или близких родственников, а также священнослужителя против тех, кто доверился ему на исповеди (Аверьянова 2004).

\section{Заключение}

Другим важным элементом следственного действия в форме опознания является выделение объектов, среди которых будет представлен опознаваемый объект. Как правило, идентифицируемому лицу предъявляется группа однородных объектов, среди которых он должен выделить объект, непосредственно связанный с данным уголовным делом, исходя из индивидуальных особенностей.

Порядок предъявления для опознания живых лиц.

Живое лицо, подлежащее идентификации, представляется сотруднику по идентификации в группе, состоящей не менее чем из трех человек. Участие в следственном действии лиц, представленных в группе с опознаваемым лицом, должно быть добровольным. При этом лица, приглашенные для участия в следственном действии, не должны быть предварительно знакомы с опознающим лицом

Однородность группы достигается приглашением людей одного пола, не имеющих резких различий во внешности. Для участия в следственном действии лица, представленные для опознания, должны быть одеты в аналогичную одежду (Баев 1997).

Очевидные отличия внешности опознанного лица от других лиц, представленных для опознания, приводят к недостоверности полученных результатов. Соответственно, результаты такой идентификации не будут признаны судом доказательствами по делу.

При этом при опознании живого лица до начала следственного действия лицо, осуществляющее уголовный процесс, позволяет опознаваемому лицу занять любое место среди других лиц, в группе которых он будет представлен опознающему лицу. В протоколе идентификации должна 
быть сделана отметка о предложении выбрать место и о самом выборе.

Во время процесса идентификации важно обеспечить безопасность идентифицирующего лица. Для этого идентификация может осуществляться в условиях, исключающих визуальное наблюдение распознавателя идентифицируемым.

В некоторых случаях опознаватель может указать, что он запомнил другие индивидуальные черты лица, которые он может распознать, - походку, голос, речь и т. д. В таких ситуациях соответствующая идентификация осуществляется по походке, голосу.

При этом в ходе предварительного допроса опознающее лицо подробно допрашивается об этих признаках. Например, если человек показал, что может узнать человека по голосу и речи, то эти особенности должны быть описаны подробно - тон, сила голоса, наличие акцента, дефекты речи (заусенец, шепелявость и т. д.), темп речи. Во время распознавания голоса и речи несколько человек произносят определенные фразы, которые запомнил распознаватель. Также возможно прослушивание специально организованных бесед нескольких лиц со следователем, прослушивание аудиозаписей, просмотр видеозаписей.

Идентификация живых лиц также может быть произведена на основании фотографий, представленных в ряде фотографий других лиц, сходных по внешнему виду, в количестве не менее трех. Такая идентификация целесообразна, если невозможно представить идентифицированное лицо. Например, подозреваемый не был задержан, но есть основания для подозрения конкретного лица.

Порядок предъявления для опознания трупа.

Как правило, труп предъявляется в единственном числе.

Однако по делам, сопряженным с большим числом жертв, предъявление для опознания трупа может производиться в общем числе погибших.

Опознающим является лицо, хорошо знавшее умершего при жизни. В таком случае предварительный допрос опознающего проводится по общим правилам. Опрашиваемый должен рассказать об обстоятельствах своего знакомства с умершим лицом, указать признаки, по которым сможет опознать его труп.

В практике встречаются также случаи, когда лицо, ведущее уголовный процесс, не владеет данными о личности умершего. Например, при обнаружении неопознанного трупа с признаками насильственной смерти в малолюдной мест- ности. В таких ситуациях труп предъявляется для опознания большому числу людей, проживающих или работающих недалеко от места обнаружения тела. Проведение предварительных допросов здесь нецелесообразно, в силу чего проводится лишь последующий допрос лица, опознавшего труп. При таком допросе свидетель должен подробно назвать те характерные признаки, которые позволили ему опознать труп.

При необходимости по указанию лица, проводящего досудебное расследование, перед показом тела опознающему специалисту специалист составляет экспертизу трупа. Основная задача, которую необходимо решить в этом случае, восстановить внешний вид идентифицируемого, что позволит надежно его идентифицировать.

Порядок предъявления для идентификации предметов и животных.

Идентификация предметов целесообразна для определения орудий и объектов преступления.

Предметы должны быть представлены в группе однотипных предметов, в количестве не менее трех. Однако для уникальных или ценных предметов властям, проводящим досудебное расследование, может быть довольно трудно отобрать аналогичные предметы. Соответственно, нормы Уголовно-процессуального кодекса Республики Казахстан в отношении таких предметов допускают идентификацию по одному предъявленному экземпляру.

Опознающий должен указать на конкретный предмет и объяснить, какие признаки и признаки, о которых он ранее свидетельствовал, позволили ему его опознать. Эти индивидуальные особенности изделия могут относиться к наименованию производителя, наличию определенных дефектов или специально изготовленных отметок, его материалу, качеству и т.д. лицо, проводящее процесс, подробно отмечает все эти особенности в протоколе идентификации.

Несмотря на то, что в УПК Республики Казахстан не говорится об опознании животных, местности или помещения, такие виды опознания встречаются в следственной практике.

Например, в уголовных делах о хищениях животных существует объективная необходимость выявления похищенных животных. Очевидно, что порядок идентификации животных и помещений мало отличается от порядка идентификации объектов.

Распознаватель заранее опрашивается лицом, ведущим процесс. В то же время он должен как можно полнее указывать характерные черты. 
По отношению к животному это должны быть такие характеристики, как порода, пол, окрас, возраст, особые приметы, в том числе и поведенческие особенности. По отношению к помещению распознаватель должен указать все признаки, которые он помнит и которые могут касаться планировки, расположения комнат, окон, дверей, используемых при строительстве и отделке строительных материалов и т. д.

При идентификации животных и помещений также должны соблюдаться требования к представлению группы однородных объектов: по- сещение ряда помещений, осмотр нескольких животных. Также можно идентифицировать объекты и животных по фотографиям и видео.

В ходе расследования используются научнотехнические средства, фиксирующие ход и результаты идентификации.

Использование научно-технических средств фиксируется в протоколе идентификации, в котором также указываются такие данные, как: идентифицируемые объекты; условия, ход и результаты идентификации; объяснения идентифицирующего лица о сделанном выборе.

\section{Литература}

Аубакирова А.А. Фиксация доказательств в криминалистике и судопроизводстве: Учебное пособие. - А., $2000 .-196$ с. Аверьянова Т.В., Белкин Р.С., Корухов Ю.Г., Росинская Е.Р. Криминалистика: Учебник для ВУЗов. - М., 2001. - 990 с. Баев О.Я. Основы криминалистики: Курс лекций / Баев О.Я. 2-е изд., перераб. и доп. - М.: Экзамен, 2003. - 320 с.

Баев О.Я. Основы криминалистики. Курс лекции. - М., 2001. -288 с.

Белкин А.Р. Теория доказательств. - М., 1999. - 429 с.

Бычкова С.Ф., Гинзбург А.Я. Следственные действия. Краткий комментарий к УПК РК - А.: ТОО «Аян Адет», 1998. $-100 \mathrm{c}$.

Васильев А.М. Тактика отдельных следственных действий. - М.: «Юридическая литература», 2000. - 312 с.

Волынский А. Ф. Технико-криминалистическое обеспечение раскрытия и расследования преступлений // Курс лекций по криминалистике. Вып. 10. - Курск, 1999. - С. 23.

Криминалистика / Под ред. А. Я. Вышинского. - М., 1935. Т. 1. - С. 67.

Клаус Дитер Поль. Естественнонаучная криминалистика. - М. 1985. - С. 15.

Гинзбург А.Я., Мажитов Ш.М. Предъявление для опознания. - Алма-Ата, 1977. - 224 с.

Гинзбург А.Я. Криминалистические основы следственных действий (по Уголовно-процессуальному кодексу Республики Казахстан) [Текст] : учебное пособие по криминалистике / А. Я. Гинзбург. - Алматы : Данекер, 2002. - 306 с.

Нубаева Г.Г. Методика расследования преступлений, связанных с насильственными действиями сексуального характера: дис. ... канд. юрид. наук. - Алматы, 2009. - 28 с.

Россинский С.Б. Следственные действия. - М.: Норма, 2018. - 240 с.

Руководство по расследованию преступлений / Руков. авт. колл. Гриненко А.В. - М.: Норма, 2002. - 768 с.

Уголовно-процессуальный кодекс Республики Казахстан от 4 июля 2014 года № 231-V.

\section{References}

Aubakirova A.A. (2000) Fiksacija dokazatel'stv v kriminalistike i sudoproizvodstve. Uchebnoe posobie. [Fixing evidence in criminalistics and legal proceedings. Textbook]. - A. - $196 \mathrm{~s}$.

Aver'janova T.V., Belkin R.S., Koruhov Ju.G., Rosinskaja E.R. (2001) Kriminalistika. Uchebnik dlja VUZov [Criminalistics. Textbook for Universities]. - M. -990 s.

Baev O.Ja. (2003) Osnovy kriminalistiki: Kurs lekcij / Baev O.Ja. 2-e izd., pererab. i dop. [Fundamentals of criminalistics: Course of lectures / Baev O. Ya. 2nd ed., reprint. and additional]. - M., Jekzamen. - $320 \mathrm{~s}$.

Baev O.Ja. (2001) Osnovy kriminalistiki. Kurs lekcii [Fundamentals of forensic science. Course of the lecture.]. - M., 2001. $-288 \mathrm{~s}$.

Belkin A.R. (1999) Teorija dokazatel'stv [Theory of proofs]. - M. - 429 s.

Bychkova S.F., Ginzburg A.Ja. Sledstvennye dejstvija. Kratkij kommentarij k UPK RK [Investigative actions. Brief commentary on the CPC of the Republic of Kazakhstan]. - A., TOO «Ajan Adet», 1998. - $100 \mathrm{~s}$.

Vasil'ev A.M. (2000) Taktika otdel'nyh sledstvennyh dejstvij [Tactics of individual investigative actions]. - M., «Juridicheskaja literatura». $-312 \mathrm{~s}$.

Volynskij A. F. (1999) Tehniko-kriminalisticheskoe obespechenie raskrytija i rassledovanija prestuplenij// Kurs lekcij po kriminalistike [Technical and forensic support of crime detection and investigation// A course of lectures on forensic scienc]. Vyp. 10. - Kursk. - S. 23.

Kriminalistika / Pod red. A. Ja. Vyshinskogo [ Criminalistics / Edited by A. ya. Vyshinsky]. - M., 1935. T. 1. - S. 67.

Klaus Diter Pol'. (1985) Estestvennonauchnaja kriminalistika [Natural science criminalistics]. - M. - S. 15. 
Ginzburg A.Ja., Mazhitov Sh.M. Predjavlenie dlja opoznanija [Presentation for identification]. -Alma-Ata, 1977. - 224 s.

Ginzburg A.Ja. (2002) Kriminalisticheskie osnovy sledstvennyh dejstvij (po Ugolovno-processual'nomu kodeksu Respubliki Kazahstan) [Tekst]: uchebnoe posobie po kriminalistike / A. Ja. Ginzburg [Criminalistic bases of investigative actions (according to the Criminal procedure code of the Republic of Kazakhstan) [Text]: textbook on criminalistics / A. ya. Ginzburg]. - Almaty: Daneker. - 306 s.

Nubaeva G.G. (2009) Metodika rassledovanija prestuplenij, svjazannyh s nasil'stvennymi dejstvijami seksual'nogo haraktera: dis. ... kand. jurid. nauk. [Methods of investigation of crimes related to sexual violence: dis. ... Cand. the faculty of law. sciences']. - Almaty. $-28 \mathrm{~s}$.

Rossinskij S.B. (2018) Sledstvennye dejstvija [Investigative actions]. - M.: Norma. - $240 \mathrm{s.}$

Rukovodstvo po rassledovaniju prestuplenij / Rukov. avt. koll. Grinenko A.V. [Manual for crime investigation / Rukov. AVT. Kol. Grinenko A.V.] . - M.: Norma, 2002. - 768 s.

Ugolovno-processual'nyj kodeks Respubliki Kazahstan ot 4 ijulja 2014 goda № 231-V.[ Criminal procedure code of the Republic of Kazakhstan No. 231-V dated July 4, 2014]. 